Please cite this article as:

Colombo G, Dell'Era C and Frattini F (2014).

Exploring the Contribution of Innovation Intermediaries to the New Product Development (NPD)

Process: a Typology and an Empirical Study.

R\&D Management, Vol. 24, No. 2, Pp. 126-146.

(DOI: 10.1111/radm.12056) 


\title{
Exploring the Contribution of Innovation Intermediaries to the New Product Development (NPD) Process: a Typology and an Empirical Study
}

\author{
Authors \\ Gabriele Colombo (Corresponding author) \\ Research Fellow \\ Politecnico di Milano \\ Department of Management, Economics and Industrial Engineering \\ Piazza L. da Vinci 32 - 20133 Milano, Italy \\ Phone: +39 022399 2763; Fax: +39 0223992720 \\ E-mail: gabriele.colombo@polimi.it

\section{Claudio Dell'Era} \\ Assistant Professor \\ Politecnico di Milano \\ Department of Management, Economics and Industrial Engineering \\ Piazza L. da Vinci 32 - 20133 Milano, Italy \\ Phone: +39 022399 2798; Fax: +39 0223992720 \\ E-mail: claudio.dellera@polimi.it \\ Federico Frattini \\ Assistant Professor \\ Politecnico di Milano \\ Department of Management, Economics and Industrial Engineering \\ Piazza L. da Vinci 32 - 20133 Milano, Italy \\ Phone: +39 022399 2796; Fax: +39 0223992720 \\ E-mail: federico.frattini@polimi.it
}




\title{
Exploring the Contribution of Innovation Intermediaries to the New Product Development (NPD) Process: a Typology and an Empirical Study
}

\begin{abstract}
In the "knowledge economy" upheld by the European Lisbon strategy, knowledge-intensive services are considered a key driver for innovation and competitiveness. A category of knowledge-intensive services that has become of utmost importance in the last few decades is New Product Development (NPD) services, which interconnect distant knowledge domains with the client firms. In addition to NPD service providers, webbased innovation intermediaries have started to help innovative firms access dispersed bodies of knowledge. Despite the heterogeneity of their characteristics, however, a clear typology of the strategies used by traditional NPD service providers and web-based intermediaries to interact with their knowledge sources and with their clients is missing. This typology would be very useful for those firms that are willing to collaborate with innovation intermediaries because it could highlight the typologies of NPD problems different intermediaries are apt to address and the managerial challenges that working with them entails. Developing such a classification framework is the main goal of this paper.

The typology proposed in this paper suggests that innovation intermediaries should be distinguished based on the following: (i) the way they Access their distributed knowledge sources and (ii) the way they Deliver value to their clients. By combining these two dimensions, 4 categories of innovation intermediaries are identified, which are named brokers, mediators, collectors and connectors. A multiple case study analysis involving 4 innovation intermediaries and 12 of their clients is presented in the paper. The analysis provides exploratory insights into (i) the typologies of NPD problems that each class of intermediaries addresses and (ii) the managerial challenges that working with each of them entails. These preliminary findings call for further theoretical and empirical research into the complex interaction among innovation intermediaries, their dispersed sources of knowledge and their clients.
\end{abstract}




\section{Introduction}

In the "knowledge economy" upheld by the European Lisbon strategy, knowledge-intensive services are considered a key driver for innovation and competitiveness (NSF, 2010). A category of knowledge-intensive services that has become of utmost importance in the last few decades is New Product Development (NPD) services. NPD service providers span multiple markets and technology domains and support their clients' NPD process with a broad array of knowledge-intensive services, such as technology and market scouting, concept generation and design, engineering and testing (Czarnitzki and Spielkamp, 2000). Because innovation is increasingly the result of novel associations among pieces of previously unrelated knowledge (Schumpeter, 1934; Kodama, 1992), NPD service providers spur innovation by connecting knowledge domains that are otherwise disconnected (Hargadon and Sutton, 1997; Hargadon, 1998).

NPD service providers adopt different intermediary strategies for connecting unrelated knowledge domains with their clients (Tran et al., 2011; Obstfeld, 2005). For instance, IDEO, one of the most well-known NPD service providers, uses its network position to acquire and recombine knowledge from disconnected domains and then offers a "turn-key" solution to its clients (Hargadon and Sutton, 1997). In contrast, Presans, a French NPD service provider whose mission is to create a linkage between business and expertise, has developed XSearch, a tool allowing automatic competence and expertise mapping (e.g., from scientific publications, patents, and corporate websites). Through this means, Presans helps its clients identify and establish relationships with experts who have different educational and professional backgrounds.

More recently, a new class of NPD service providers has emerged that takes advantage of the increasing pervasiveness of Web 2.0 technologies. These so-called web-based intermediaries (Colombo et al., 2013) offer their clients the opportunity to access the expertise and creativity of large communities of firms and, above all, of individuals active in heterogeneous and geographically distant fields (Jeppsen and Lakhani, 2010; Boudreau et al., 2011). For instance, IDEO expanded its business model in 2010 by launching OpenIDEO, an online community where people are encouraged to create solutions to some of the world's toughest innovation challenges. Community members can contribute in a variety of ways, e.g., by submitting inspirational observations, photos, ideas, business models and snippets of code. 
It is clear that firms today are exposed to a broad and heterogeneous range of innovation intermediaries ${ }^{1}$ with which they can collaborate along the NPD process in an attempt to improve their product innovation performance. Nevertheless, there is a lack of understanding of (i) the strategies that different categories of intermediaries use when they interact with their knowledge sources and with their clients and (ii) the classes of NPD problems they address and the challenges client firms have to overcome when interacting with the service provider (Verona et al., 2006). This understanding would be very important for those firms that wish to extract the maximum value from their collaboration with an innovation intermediary and to design effective policies that foster the contribution of innovation intermediaries to industrial innovation.

The first objective of this paper is to take a step toward filling these gaps by developing a typology of the strategies innovation intermediaries adopt when they interact with their knowledge sources and with their clients. Second, this study aims to provide a preliminary understanding of (i) the contributions different classes of innovation intermediaries make to the NPD process of their clients by focusing on the categories of NPD problems they are able to address and (ii) the capabilities firms deploy when they collaborate with intermediaries adopting different intermediary strategies. To pursue these goals, an exploratory multiple case study involving 4 innovation intermediaries (i.e., Continuum, Material ConneXion, Aedo-to and Takeacoder) and 12 of their clients is presented after the development of the typology.

In order to achieve the above mentioned research objectives we have organized the paper as follows. The next section briefly reviews the relevant literature. Afterwards, the theoretical framework and the research methodology adopted in the empirical analysis are illustrated. The fifth section presents and discusses the results of the empirical analysis. Finally, conclusions are drawn, and avenues for future research are outlined.

\section{Literature review}

\subsection{NPD service providers}

\footnotetext{
${ }^{1}$ In this paper, we use the term innovation intermediary to indicate both NPD service providers and web-based innovation intermediaries.
} 
According to Howells (2006), innovation intermediaries can be defined as agents or brokers "helping to provide information about potential collaborators; brokering a transaction between two or more parties; acting as a mediator, or go-between, bodies or organizations that are already collaborating; and helping find advice, funding and support for the innovation outcomes of such collaborations" (Howells, 2006: 720). The role of intermediaries in the innovation process has been studied from different perspectives in various research fields (Howells, 2006): (i) technology transfer and diffusion (Seaton and Cordey-Hayes, 1993); (ii) innovation management (Hargadon and Sutton, 1997; McEvily and Zaheer, 1999); (iii) systems and networks (Stankiewicz, 1995; Lynn et al., 1996); and (iv) service organizations, particularly knowledge-intensive business services, or KIBS (Miles, 2000; O’Farrell and Wood, 1999; Chiesa et al., 2007; Abecassis-Moades et al., 2012).

Specifically, innovation management scholars have paid attention to the brokering role played by innovation intermediaries. NPD service providers are defined as "organizations that span multiple markets and technology domains and innovate by brokering knowledge from where it is known to where it is not" (Hargadon, 1998: 2). They exploit their unique market position by acquiring knowledge from different domains, recombining it and delivering it in the form of a solution to firms' innovation problems (Hargadon 1998; Hargadon and Sutton 2000).

Prior research shows that NPD service providers can adopt very different strategies when they interact with their sources of knowledge (Chiaroni et al., 2008). For instance, Hargadon and Sutton (2000) highlight the brokering role performed by NPD service providers, while Obstfeld (2005) suggests that such intermediaries play a bridging function by introducing or facilitating interactions between parties that would otherwise be disconnected. Moreover, some studies have explored the different ways through which NPD service providers create value for their clients, from increasing product development speed to offering new and enhanced product attributes (Tran et al. 2011). Similarly, Gassman et al. (2011) identify three mechanisms through which NPD service providers add value to their clients in cross-industry innovation processes, which are called innovation broadener, leverager, and multiplier. 
According to the best knowledge of the authors, however, no systematic effort has been made to propose a typology of the different strategies NPD service providers adopt when they interact with their sources of knowledge and with their clients and to discuss the implications of each strategy for the interaction between the intermediary and its clients.

\subsection{Web-based intermediaries}

In the last few years, a new category of innovation intermediaries has emerged that leverages the increased pervasiveness of Web 2.0 technologies. These are called web-based intermediaries (Colombo et al., 2013), and their mission is to offer their clients the opportunity to access the power and creativity of large communities of individuals, known as solvers, with educational and professional experience in different geographical and disciplinary areas. Several studies have shown that these intermediaries can be more effective than traditional NPD service providers because of their superior ability in leveraging their network position (Verona et al., 2006).

Because of the growing presence of web-based intermediaries, scholars have started to investigate which factors affect their ability to support innovation. Among others, Terwiesch and $\mathrm{Xu}$ (2008) show that increasing the number of solvers benefits innovation by broadening the search for solutions, therefore increasing the ability of the intermediary to access different knowledge domains. Boudreau et al. (2011) find similar results when analyzing a sample of 645 innovation problems posted on Topcoder, while Jeppesen and Lakhani (2010) explain that the success of such intermediaries lies in their ability to attract specialized solvers with a range of diverse scientific interests.

Similarly to NPD service providers, research has documented the existence of different strategies used by web-based intermediaries to access dispersed knowledge and transfer it to their clients (Chesbrough, 2006; Huston and Sakkab, 2006; Verona et al., 2006; Pisano and Verganti, 2008; Colombo et al., 2013). Despite the importance of the topic, however, a typology of these strategies is lacking (Verona et al., 2006). Moreover, there is no attempt in the literature to provide an integrative and comparative view of the approaches adopted by traditional NPD service providers vis-à-vis web-based innovation intermediaries, even though 
firms confronted with an innovation problem and that are willing to collaborate with an intermediary have two options from which to choose, namely, relying on a more traditional NPD service provider or engaging in a collaboration with a web-based intermediary. Therefore, having an understanding of the categories of innovation problems each type of intermediary is able to address and the capabilities firms have to deploy to improve the chances of the collaboration's success is an important aspect for R\&D and innovation managers today.

\section{Theoretical framework}

According to Hargadon and Sutton (1997), the competitive advantage of an innovation intermediary depends "on both its network position as a broker and on an organizational memory that allows it to acquire, retain, and retrieve new combinations of information obtained through such a position." (Hargadon and Sutton, 1997: 717). This suggests that innovation intermediaries use and offer to their clients two different types of knowledge: (i) know-who, which refers to knowledge about who knows what and is a result of their network position (Lundvall and Johnson, 1994) and (ii) know-how, which refers to knowledge regarding the performance of an action and is related to the ability of an innovation intermediary to access and recombine different sources of knowledge to propose a solution to a specific problem (Lundvall and Johnson, 1994; Hargadon and Sutton, 1997). Know-how and know-who represent two forms of tacit knowledge, as defined by Polanyi (1966), because they are rooted in practical experience and in social interactions and, therefore, can be transferred only through close relationships with the recipients of this knowledge (Lundvall and Johnson, 1994).

Due to the challenges sharing tacit knowledge entails, research has given particular attention to the processes innovation intermediaries adopt to transfer such knowledge to their clients (Hargadon and Sutton, 1997; Hargadon and Sutton 2000; Verona et al., 2006; Jeppesen and Lakhani, 2010). In particular, research suggests that the transfer process can be divided into two main steps: (i) access to and acquisition of dispersed knowledge and (ii) absorption, implementation and delivery of this knowledge. In the remainder 
of the paper, we label these two dimensions of the intermediary process access and delivery. Access captures differences in how innovation intermediaries interact with their network of knowledge sources, whereas delivery considers heterogeneity in how innovation intermediaries interact with their clients to bring knowledge to them.

Following this line of reasoning, it can be argued that innovation intermediaries can use the two types of knowledge (know-who and know-how) along both the access and delivery steps of the intermediary process. This understanding sets the foundation for our typology:

- Concerning the access dimension, know-who and know-how can be interpreted respectively as sources and proposals accessed by the innovation intermediary. Indeed, the literature indicates that some innovation intermediaries actively search for the most appropriate knowledge sources (know-who) based on their clients' needs (Hargadon and Sutton, 1997). These intermediaries know exactly who has the right pieces of knowledge required to address their client's innovation problem. In contrast, other innovation intermediaries, especially those operating on the web, simply ask their entire community of solvers to submit proposals or solutions for a specific problem addressed by their clients (Jeppesen and Lakhani, 2010; Boudreau et al., 2011). They do not know exactly who has the right competencies to address a specific problem, but they have the capability to identify and access the right pieces of knowledge (knowhow). Of course, this is possible thanks to their ability to solicit proposals from a very large network of experts active in different knowledge domains.

- Concerning the delivery dimension, know-who and know-how can be interpreted respectively as contacts and solutions delivered by the innovation intermediary. Research shows that some innovation intermediaries create a link between the knowledge sources and their clients, facilitating the cooperation (Burt, 2004; Obstfeld, 2005; Singh and Fleming, 2010) and delivering to their clients the contacts (knowwho) that helps them to establish a relationship with the most appropriate sources of knowledge. Instead, other innovation intermediaries provide their clients with a practical "turn-key" solution (know- 
how) to their needs (Hargadon and Sutton, 1997; Hargadon and Sutton, 2000; Hargadon, 1998; Jeppesen and Lakhani, 2010)..

By combining these insights, it is possible to identify four classes of innovation intermediaries (see Figure 1).

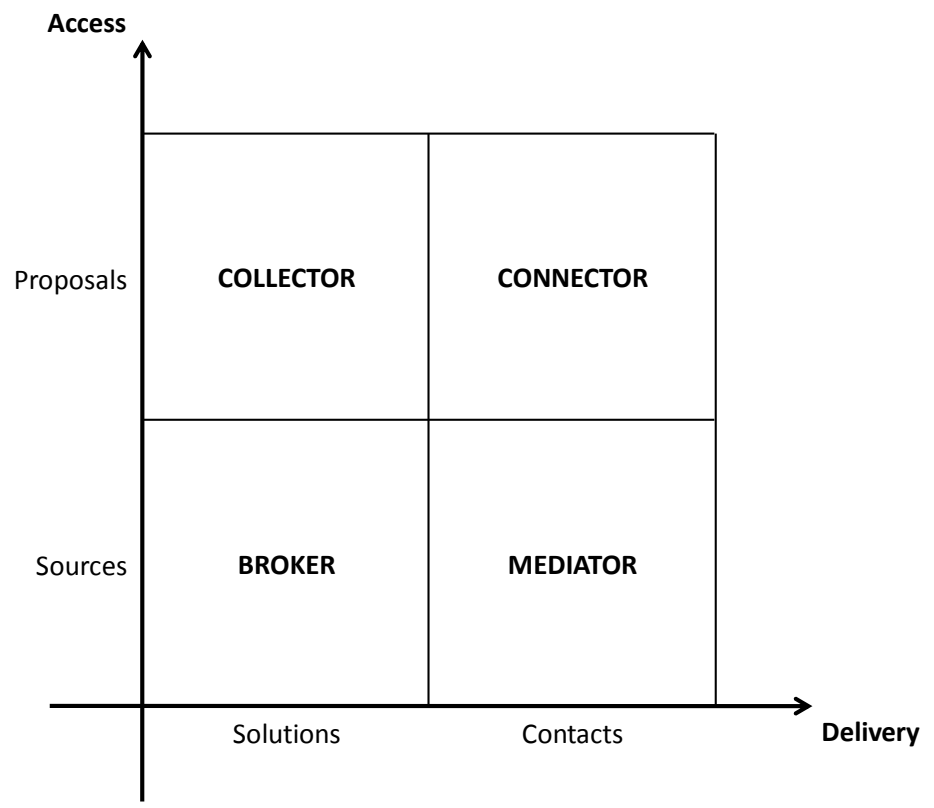

Figure 1: Typology of innovation intermediaries

Collectors are those intermediaries that, starting from the need of their clients, access their network of potential solvers soliciting proposals. They encourage their network of solvers to deliver solutions that are needed by their clients. Collectors transfer these solutions to their clients, who can select the best solution based on their idiosyncratic needs. Brokers are similar to collectors in that they provide their clients with solutions that are ready to be used in their innovation process. However, they do not solicit ideas and suggestions from their network of knowledge sources but selectively access the sources of knowledge that are deemed most appropriate. Mediators are those intermediaries that, starting from an understanding of their clients' needs, identify which sources of knowledge within their broad network are more appropriate 
and establish a relationship between them and their clients. They provide therefore to their clients the appropriate contacts to address their innovation needs. Finally, Connectors access their network of solvers and ask to propose themselves as a potential partner to collaboration with the clients. After having received all the applications from the solvers, Connectors disclose them to the client that can choose the contact of the solver that is more appropriate in light of its specific need.

Starting from this typology, the analysis presented in the remainder of the paper provides exploratory evidence regarding the following: (i) what innovation problems each category of innovation intermediaries depicted in Figure 1 is used to address and (ii) what capabilities firms have to deploy when they collaborate with innovation intermediaries belonging each class reported in Figure 1. The core theoretical framework informing the empirical study is summarized in Figure 2.

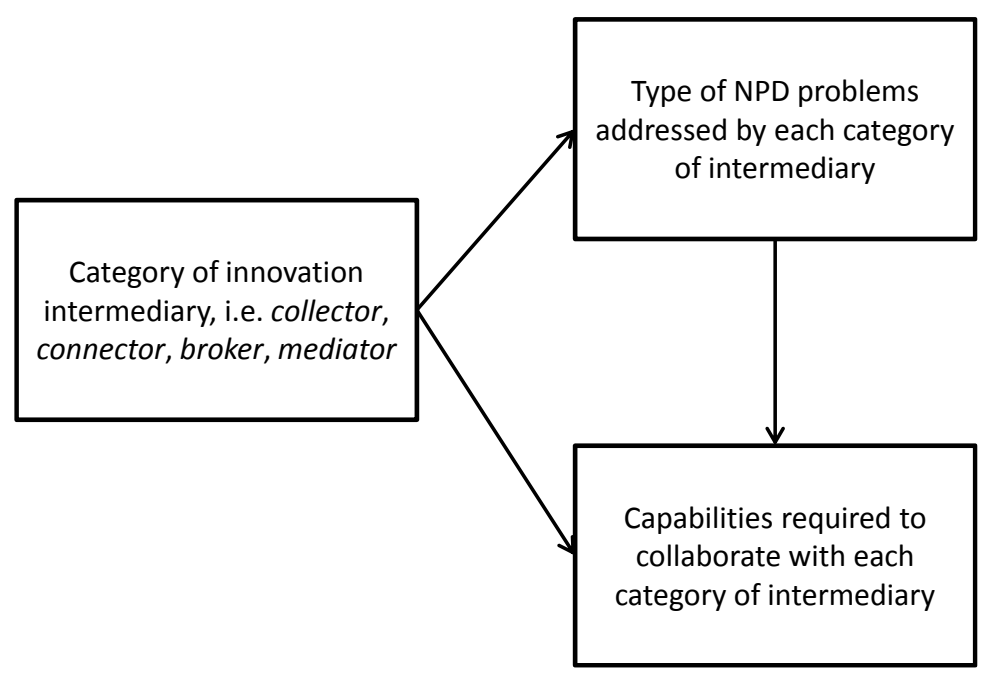

Figure $\mathbf{2}$ The core theoretical framework

Concerning the capabilities firms need to benefit from collaboration with different categories of innovation intermediaries, our analysis draws from research on the concept of absorptive capacity (Cohen and Levinthal, 1990), according to which a firm's ability to absorb external knowledge (e.g., provided by an innovation intermediary) depends on its level of absorptive capacity, which should be conceived as a set of organizational capabilities concerning the acquisition and assimilation of external knowledge and its 
transformation into new products, services and processes (Eisenhardt and Martin, 2000; Kogut and Zander, 1992). This set of capabilities has also been labeled as combinative capabilities (Kogut and Zander, 1992), and can be classified as (i) coordination capabilities, (ii) systems capabilities and (iii) socialization capabilities. Coordination capabilities are those that "enhance knowledge absorption through relations between members of a group" (Van den Bosch et al., 1999: pp. 556). These capabilities refer to specific organizational mechanisms, such as cross-functional interfaces, participation in decision making and job rotation, which favor knowledge sharing and absorption within an organization (Henderson \& Cockburn, 1994; Van den Bosch et al., 1999). System capabilities allow firms to "program behaviors in advance of their execution and provide a memory for handling routine situations" (Jansen et al., 2005 :pp.1002). They enable firms to develop organizational routines that lower the effort spent on decision making by providing an efficient structure for collective action (Cohen \& Bacdayan, 1994). System capabilities also improve a firm's ability to efficiently tackle unexpected situations that might surface during collaboration with innovation intermediaries, thus streamlining the assimilation and use of external knowledge. Finally, socialization capabilities "create broad, tacitly understood rules for appropriate action" (Jansen et al., 2005: pp.1003) and contribute to establish shared values and dominant codes of communications. This benefit favors communication among people with different educational backgrounds and professional experience and therefore eases the interaction with providers of knowledge coming from different educational and geographical backgrounds (Chao et al., 1994; Fisher, 1986). The importance of looking at the capabilities firms have to deploy to extract the maximum value from collaboration with innovation intermediaries is due to the tacit nature of the knowledge they exchange with their clients, which requires particular managerial attention to be properly transferred and assimilated (Bianchi et al., 2011). Moreover, the literature on organizational integration in NPD processes (e.g., Millson and Wilemon, 2002; Souder et al., 1998) points to the importance of cooperation and communication between different functions (e.g., R\&D, marketing and operations) and with external organizations participating in the NPD process for the successful completion of the innovation process. Capabilities that ease the interactive nature of this process are therefore of particular importance during collaboration with innovation intermediaries. The empirical analysis reported 
in the remainder of the paper will suggest that each of the capabilities presented above becomes especially critical when a firm collaborates with a particular category of innovation intermediaries.

\section{Methodology}

We used a multiple case study methodology for our empirical analysis (Yin, 1984). We believe this approach is well suited to the exploratory nature of our investigation because it allows an exploration of the phenomenon of interest, i.e., the interaction among different categories of innovation intermediaries and their clients in its whole complexity (Eisenhardt and Graebner, 2007). Our case studies have an exploratory intent and are retrospective in nature (Yin, 1984). We studied 4 innovation intermediaries that adopt different intermediary strategies, and we collected information from 12 of their clients. In particular, we theoretically sampled 4 cases of intermediaries that are heterogeneously distributed along the Access and Delivery dimensions of the typology presented above (Figure 1). This "polar types" theoretical sampling (Eisenhardt and Graebner, 2007) enables us to study the phenomenon of interest under particularly insightful circumstances and to more easily unearth relationships between the type of innovation intermediary and the way in which the interaction with client firms takes place.

We relied on a panel of 10 experts to sample the cases. The panel included 4 professors working at Politecnico di Milano in the Department of Management, Economics and Industrial Engineering and in the Department of Industrial Design; 4 managers from international manufacturing firms with responsibilities for collaborative R\&D projects; and 2 managers from design agencies involved in the supply of knowledgeintensive services. Each expert was asked to indicate 4 innovation intermediaries they were knowledgeable about, resulting in a list of 28 intermediaries. The list was sent back to the experts, with the request to classify each of them in one of the four quadrants of our typology (Figure 1). At least one of the authors contacted each expert to explain our framework and the criteria used to classify the intermediaries. All the experts agreed on the position of 23 intermediaries within our typology. We started from this list of 23 intermediaries and selected only those with a focused and easily observable strategy (Eisenhardt, 1989), as they offered a 
core and identifiable service that was not bundled with additional open Innovation or consultancy activities. We paid special attention to building a balanced sample of cases along the four quadrants of our typology to allow for insightful cross-case comparisons. This step led us to a list of 16 intermediaries. Finally, we selected those intermediaries where direct interviews could be conducted in the native language of the authors to ease data collection and analysis. Ultimately, we restricted our analysis to the 4 intermediaries reported in Table 1. The remaining 12 cases that were not studied through direct interviews are reported in Appendix A, with synthetic information gathered from secondary data sources. 


\begin{tabular}{|c|c|c|}
\hline Intermediary & Access & Delivery \\
\hline $\begin{array}{l}\text { BROKER: Continuum } \\
\text { [continuuminnovation.com] } \\
\text { Continuum Innovation is a design and innovation consultancy firm based in the U.S., with } \\
\text { other offices in Italy, Japan and China. The company's core disciplines include, for } \\
\text { example, brand experience, design strategy, organisational innovation and product } \\
\text { innovation. Continuum was founded in } 1983 \text {, and it currently employs approximately } 180 \\
\text { people, with an annual turnover of about } 2 \text { million } € \text {. It has worked with clients in several } \\
\text { industries: medical, consumer, computer, automotive, hospitality and financial services. } \\
\text { Continuum has won } 14 \text { IDSA/BusinessWeek International Design Excellence Awards since } \\
2003 \text { and has developed more than } 330 \text { design and utility patents. }\end{array}$ & $\begin{array}{l}\text { Access Sources } \\
\text { Continuum establishes collaborations with its clients } \\
\text { according to a standard sequence of activities. Specifically, } \\
\text { the collaboration starts with a kick-off meeting in which } \\
\text { the client exposes a rough brief of the project. After the } \\
\text { kick-off meeting, the collaboration process goes through a } \\
\text { very critical activity called Alignment and Learning. The } \\
\text { aim of this phase is twofold. First, Continuum gathers and } \\
\text { interprets, through several face-to-face personal contacts } \\
\text { with the client's managers, the client's needs and } \\
\text { diagnoses its organisational culture (Alignment). Then, the } \\
\text { characteristics of the market where the client sells its } \\
\text { products are thoroughly investigated by Continuum, with } \\
\text { the aim to identify useful insights for the development of } \\
\text { the new product (Learning). }\end{array}$ & $\begin{array}{l}\text { Delivery Solutions } \\
\text { Continuum acts as a "knowledge broker", spanning } \\
\text { multiple markets and technology domains and innovating } \\
\text { by brokering knowledge from where it is known to where } \\
\text { it is not. The opportunity to collaborate with companies } \\
\text { that operate in different industries allows Continuum to } \\
\text { transfer solutions from one sector to another. In } \\
\text { collaborating with heterogeneous partners, Continuum not } \\
\text { only increases its recombination possibilities but also } \\
\text { recognises opportunities ahead of competitors. } \\
\text { Collaboration with heterogeneous partners may lead to } \\
\text { constructive conflict, thereby increasing Continuum's } \\
\text { problem-solving capabilities and approaching new } \\
\text { opportunities through new frameworks. }\end{array}$ \\
\hline $\begin{array}{l}\text { MEDIATOR: Material ConneXion } \\
\text { [www.materialconnexion.com] } \\
\text { Material ConneXion is a global materials consultancy that innovates through smart } \\
\text { materials thinking. Built on the belief that Every Idea has a Material Solution }{ }^{T M} \text {, they advise } \\
\text { Fortune } 500 \text { companies, smaller forward-thinking companies, and government agencies } \\
\text { seeking a creative or competitive edge through strategic material selections. With offices } \\
\text { in New York, Bangkok, Cologne, Daegu and Milan, Material ConneXion's international } \\
\text { network of material specialists provides a global, cross-industry perspective on materials, } \\
\text { sustainable alternatives, and their potential uses. Material ConneXion helps companies } \\
\text { innovate through smart materials thinking. }\end{array}$ & $\begin{array}{l}\text { Access Sources } \\
\text { Material ConneXion's Materials Library is the largest library } \\
\text { of advanced, innovative, sustainable materials and } \\
\text { processes in the world with over } 5000 \text { materials. On-site } \\
\text { access allows clients to conduct research in the physical } \\
\text { archives. Online access gives the user access to Material } \\
\text { ConneXion's online database of innovative materials. } \\
\text { Materials are chosen through a strict review process. } \\
\text { Material ConneXion's consulting services help expand } \\
\text { design opportunities for a wide range of clients - from } \\
\text { Fortune } 500 \text { companies to progressive, forward-thinking } \\
\text { companies that understand the key to innovation lies with } \\
\text { the right material choices. }\end{array}$ & $\begin{array}{l}\text { Delivery contacts } \\
\text { Material ConneXion aims to connect material suppliers and } \\
\text { manufacturing companies, providing value-added services. } \\
\text { They continuously collect and analyse information about } \\
\text { new materials in order to provide the current state-of-the- } \\
\text { art in the materials field. Specifically, they support } \\
\text { manufacturers in the identification of materials suppliers } \\
\text { that can enable their innovations. For example, in the case } \\
\text { of GINA (concept car designed by Chris Bangle and } \\
\text { presented by BMW in 2008; GINA represents a visionary } \\
\text { shape-shifting sports car made from polyurethane-coated } \\
\text { Lycra stretched over a wire aluminium frame), Material } \\
\text { ConneXion proposed an interesting selection of extremely } \\
\text { tear-proof and resistant textiles with interesting details } \\
\text { about associated manufacturers. }\end{array}$ \\
\hline $\begin{array}{l}\text { COLLECTOR: Aedo-to } \\
\text { [www.aedo-to.com] } \\
\text { Aedo-to.com is a design community that facilitates the interaction between industry and } \\
\text { designers. Aedo-to gathers the community of designers in the "internet time", spreading }\end{array}$ & $\begin{array}{l}\text { Access Proposals } \\
\text { Every designer, from every country in the world, can } \\
\text { engage in this kind of competition. The process is quite } \\
\text { simple. Companies that have a design project to develop, } \\
\text { that is, the seeker, post a brief on Aedo-to's website. The }\end{array}$ & $\begin{array}{l}\text { Delivery Solutions } \\
\text { Solvers work separately on the project and submit their } \\
\text { solutions to the design problem. The seeker screens all the } \\
\text { solutions submitted and chooses the best one. The }\end{array}$ \\
\hline
\end{tabular}




\begin{tabular}{|c|c|c|}
\hline $\begin{array}{l}\text { information and know-how to the design world and the design-oriented manufacturers. } \\
\text { Aedo-to.com was born in January } 2001 \text { as a creativity portal. Aedo-to relates with } \\
\text { companies and designers. The idea is simple: talented designers are everywhere, and } \\
\text { companies, to compete on the market, have to develop new ideas. }\end{array}$ & $\begin{array}{l}\text { brief describes, in detail, what the seeker wants and the } \\
\text { characteristics of the project. }\end{array}$ & $\begin{array}{l}\text { developer of the winning solution is awarded with a } \\
\text { monetary prize. }\end{array}$ \\
\hline $\begin{array}{l}\text { CONNECTOR: Takeacoder } \\
\text { [www.takeacoder.com] } \\
\text { Takeacoder is a platform that wants to change the rules of business giving to enterprises, } \\
\text { entrepreneurs and common people the chance to deliver their innovative ideas at the top; } \\
\text { leveraging the best of breed of worldwide human skills and capabilities and streamlining } \\
\text { the actual process of delivery. Takeacoder intends to redesign the business professional } \\
\text { services market, giving to professionals a marketplace where they can sell their skills and } \\
\text { knowledge to enterprises inside a framework that maximises value for both. }\end{array}$ & $\begin{array}{l}\text { Access Proposals } \\
\text { On Takeacoder firms, mainly SMEs, post a short } \\
\text { description, called a brief, of the problem they want to } \\
\text { solve. The solvers (anyone in the world can register as } \\
\text { solvers on Takeacoder) look at the description of the } \\
\text { problems posted on the platform and decide the ones they } \\
\text { want to try to solve. }\end{array}$ & $\begin{array}{l}\text { Delivery Contacts } \\
\text { The solvers submit their bids to the problem's owner, that } \\
\text { is, the seeker, describing their competences, their past } \\
\text { experiences, the delivery time and the amount of money } \\
\text { they want for working on the solution of the problem. The } \\
\text { seeker examines the bids and selects the best solver, that } \\
\text { is, the solver who will work on the brief. After the selection } \\
\text { of the bid that best matches the seeker's needs, the solver } \\
\text { will start work. }\end{array}$ \\
\hline
\end{tabular}

Table 1: Case study overview 
Regarding data collection, for each innovation intermediary reported in Table 1, at least two interviews with

founders and senior managers were conducted to collect empirical evidence concerning how the intermediary interacts with its sources of knowledge and clients (to corroborate the position in our typology) and, most importantly, to understand which types of NPD problems it helps clients to address. Appendix B reports the protocol used to support these interviews and to enhance the reliability of the study (Yin, 1984). During the interviews with founders and senior managers, we identified 3 NPD projects for each intermediary that were representative of its intermediary activity (see Table 2 for a brief description of the 12 projects identified).

\begin{tabular}{|c|c|}
\hline Intermediary & Brief description of the projects \\
\hline \multirow{3}{*}{ Continuum } & $\begin{array}{l}\text { In 2004, Continuum collaborated with a leading Italian manufacturer in the shoe industry. In the early } 2000 \text { s, its market } \\
\text { position worsened due to increased competition. To face this challenge, it collaborated with Continuum to reinforce its } \\
\text { technical credibility trough the commercialization of an innovative shock absorption system for its tennis shoe line. }\end{array}$ \\
\hline & $\begin{array}{l}\text { In 2006, Continuum collaborated with the worldwide market leader in the vendor machine industry. It was ahead of its } \\
\text { competitors in terms of technical and innovation capabilities. It engaged Continuum to develop scenarios of what the } \\
\text { vending machine of the future would be to maintain its leading market position. }\end{array}$ \\
\hline & $\begin{array}{l}\text { In } 2005 \text {, Continuum collaborated with one of the world's leading international appliance companies. It started the } \\
\text { collaboration with Continuum to make a synthesis of the results it has achieved after a year of internal concept } \\
\text { generation activities. It asked to develop an operating model, i.e., a prototype that looks and works like a new product, } \\
\text { for a new household appliance. }\end{array}$ \\
\hline \multirow{3}{*}{$\begin{array}{l}\text { Material } \\
\text { ConneXion }\end{array}$} & $\begin{array}{l}\text { GINA is an unusual car concept from BMW that was first presented to the public in July 2008. The idea for the car's fabric } \\
\text { was inspired by a collaboration with Material ConneXion in New York. The idea was inspired by an exhibition created by } \\
\text { Material ConneXion in New York (Tensions in Architecture). During the research process, Material ConneXion of New York } \\
\text { proposed to BMW an interesting selection of extremely tear-proof and resistant textiles with associated manufacturers. }\end{array}$ \\
\hline & $\begin{array}{l}\text { In April 2010, PUMA previewed a sustainable packaging and distribution system created by industrial designer Yves Behar } \\
\text { that will significantly reduce the amount of waste and } \mathrm{CO} 2 \text { emissions compared with that generated by traditional } \\
\text { product packaging, such as shoe-boxes and polyethylene apparel bags. The bag is made of non-woven polyester } \\
\text { consisting of polypropylene and is recyclable. Material ConneXion advised on the material, fabrication methods, and } \\
\text { sustainability process. }\end{array}$ \\
\hline & $\begin{array}{l}\text { When it developed the Uruku line of makeup, Aveda was compelled to create a cosmetic packaging made entirely of } \\
\text { recycled materials. To find the right solution, Aveda's design consultant Harry Allen asked Material ConneXion for help } \\
\text { sourcing a material that was visually appealing as well as compatible with Aveda's sustainability requirements and } \\
\text { existing injection and compression molds. }\end{array}$ \\
\hline \multirow{2}{*}{ Aedo-to } & $\begin{array}{l}\text { Aedo-to.com collaborated with an Italian manufacturer leader in household accessories. The intermediary launched a } \\
\text { competition open to all women in the world with the aim to include new perspectives in its design process, as household } \\
\text { accessories had always been designed by men. }\end{array}$ \\
\hline & $\begin{array}{l}\text { In 2009, Aedo-to.com collaborated with a leading Japanese electronics company to design a new digital audio player. } \\
\text { Aedo-to.com was able to solicit numerous solutions from designers around the world. Identifying the best idea was a long } \\
\text { process due to the high number of solutions received. }\end{array}$ \\
\hline
\end{tabular}




\begin{tabular}{|l|l|}
\hline $\begin{array}{l}\text { Aedo-to.com collaborated with an important firm leader in the protective clothing industry. The project concerned the } \\
\text { design of a new type of sun-glasses that can be worn under the crash helmet. Even in this case, the company benefitted } \\
\text { from a large set of different designs. }\end{array}$ \\
\hline TakeACoder helped an Italian start-up identify a specialized programmer to develop two iPhone applications. The \\
peculiarities of such applications are related to the use of the newtonmeter and all other mobile spatial and motion \\
sensors available on the iPhone to give a Wii-like experience. \\
Coder $\mathrm{A}$ \\
$\begin{array}{l}\text { TakeACooder connected an e-commerce company with the professor of a well-known business school to develop a 3-5 } \\
\text { year business plan for the company. }\end{array}$ \\
\hline $\begin{array}{l}\text { TakeACoder collaborated with a company to develop a Project Management Service software similar to basecamp.com by } \\
\text { connecting the company to different expert programmers. }\end{array}$
\end{tabular}

Table 2: Summary of the projects undertaken by the intermediaries with their clients

We contacted the client firms involved in these projects and interviewed at least two informants for each of them (typically, the project leader and a senior manager). During this second round of interviews, we corroborated the findings that emerged from the interviews with the intermediaries by collecting data about the type of NPD problems that were addressed during the collaboration. Comparing the information collected from the intermediaries and from their clients was particularly helpful to increase the validity of our research (Yin, 1984). Moreover, the second round of interviews allowed us to collect data about the barriers the clients' firms had to overcome to ensure smooth progress of the collaboration with the innovation intermediary and the capabilities required to do so. The interview protocol in Appendix C reports the open-ended questions posed to the informants from the client firms.

The interviews lasted between 1 and 2 hours, and they were tape recorded and transcribed. In total, the dataset comprised over 27 hours of interviews and 140 pages of transcripts. Information collected through direct interviews was triangulated using documents provided by the innovation intermediaries and their clients (e.g., project reports, intermediate deliveries, contractual agreements between the intermediary and its clients) and publicly available sources (e.g., websites, press articles). Again, this served to increase the construct validity of the study (Yin, 1984).

The data analysis was mainly based on interview transcripts. Each case was analyzed by at least two authors, which further enhanced the construct validity (Yin, 1984). Starting from the transcripts, a data matrix was developed, as recommended by Miles and Huberman (1994). The transcripts and the matrix were analyzed iteratively and separately by the authors. We looked for and found regularities across cases. The analysis of 
the across-case matrix served to identify recurrent patterns in our data, allowing us to suggest the existence of significant differences in the type of NPD problems solved by the intermediary and the critical capabilities required to collaborate with it, depending on the position of the intermediary in our typology. These structured procedures for data analysis served to ensure the internal validity of our study (Yin, 1984). Finally, follow-ups with the interviewed people were conducted to further increase the validity of the research.

Figure 3 provides a synoptic view of how the data analysis process and the interviews with the key informants enabled us to build an exploratory understanding of the key elements of our theoretical framework.

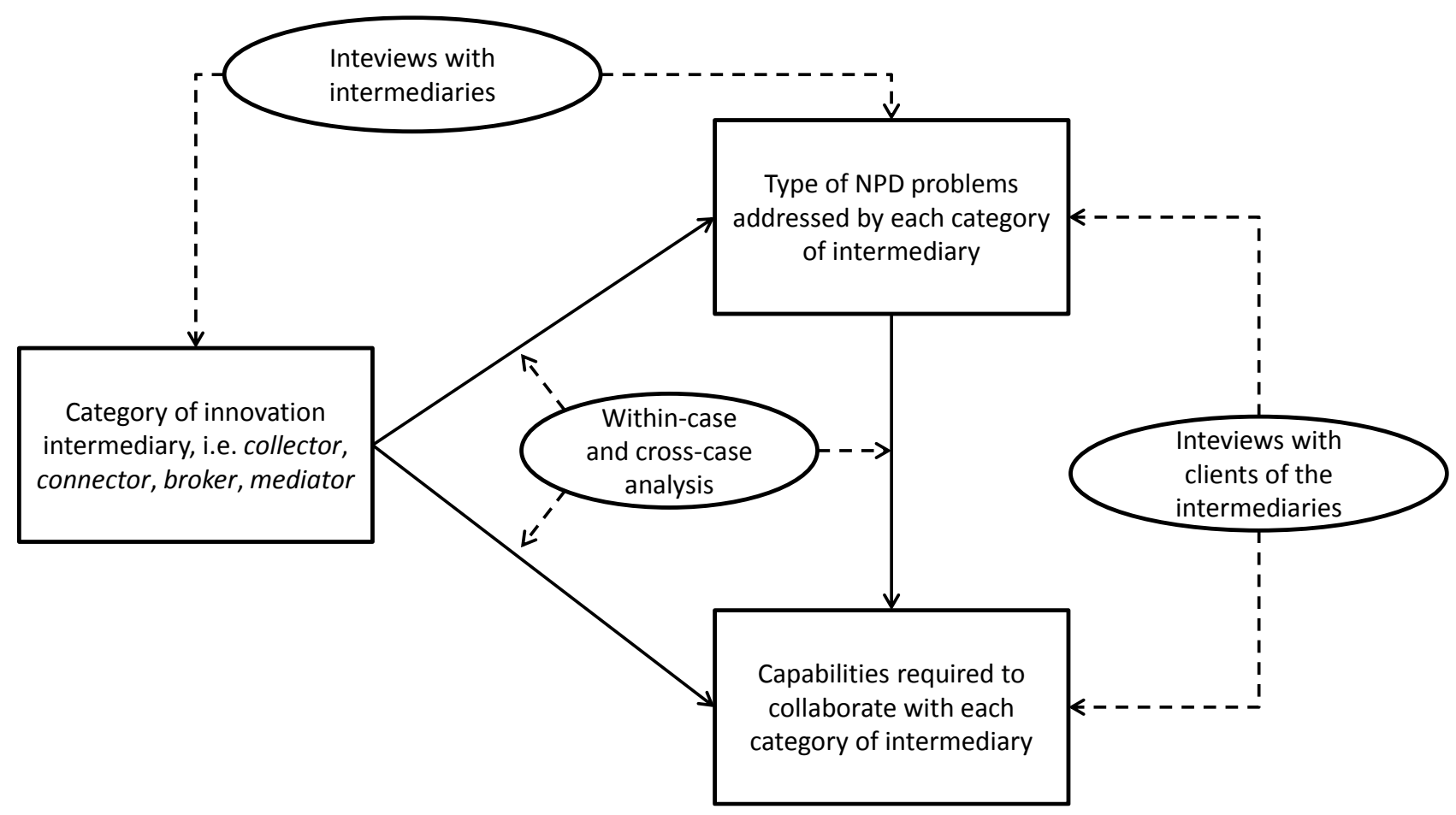

Figure 3 The core theoretical framework and the empirical analysis

It should be noted here that it is not possible to statistically generalize results from an exploratory case study analysis (Yin, 1984). Our aim is to make analytical and theoretical generalizations of the existing body of knowledge regarding the strategies through which NPD service providers and web-based intermediaries access knowledge and deliver it to their clients and, most importantly, the types of NPD problems they address and the capabilities required of the client firm to interact with them. It is our intent that these findings inform future theoretical and empirical studies regarding the interaction between innovation 
intermediaries and their clients, but we recognize that they cannot be generalized to populations of firms or markets.

\section{Results and discussion}

This section presents and discusses the results of our multiple case study analysis organized around the four categories of innovation intermediaries identified in the typology presented in Figure 1.

\subsection{Broker}

Brokers (see Figure 4) choose the most appropriate sources of knowledge to address the needs of their clients based on a careful understanding of the latter (Access Sources), to acquire pieces of knowledge from these sources and to recombine them to provide a "turn-key" solution to their clients (Delivery Solutions). The broker strategy is usually adopted by traditional NPD service providers such as Continuum, IDEO, Frog Design and Future Concept Lab (see Appendix A).

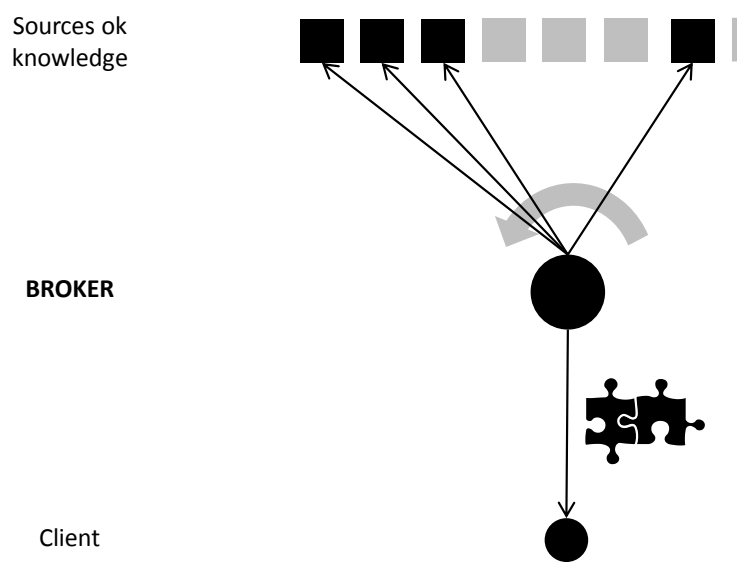

Figure 4: Innovation Intermediary - Broker

The distinctive characteristic of brokers is their ability to access and acquire deep knowledge distributed in different domains and transfer it to their clients by delivering solutions. Brokers know exactly who has the 
right pieces of knowledge required to address the client's problem, and hence they can straightforwardly access such sources of knowledge. Starting from these premises, our analysis suggests that brokers help their clients solve complex innovation problems, characterized by unclear technical and market requirements, where a deep knowledge of different scientific and technological domains is required. As stated on the Continuum website: "With designers and strategists located around the world, Continuum solves complex problems by understanding what is meaningful to people". Similarly, IDEO claims in its manifesto: "We identify new ways to serve and support people by uncovering latent needs, behaviors, and desires. [...] Design thinking is a deeply human process that taps into abilities we all have but get overlooked by more conventional problem-solving practices. It relies on our ability to be intuitive, to recognize patterns, to construct ideas that are emotionally meaningful as well as functional, and to express ourselves through means beyond words or symbols ". As noted by the Design Manager of Continuum, the fact that the company has worked with clients in many different industries (including medical, consumer, computer, automotive, hospitality, and financial services) allows it to easily transfer solutions from one sector to the other, by connecting knowledge domains that are otherwise unconnected. This also emerged from our deeper analysis of the three projects conducted by Continuum. The client firms we interviewed admitted that they decided to rely on Continuum because they knew that, to identify a valuable and ready-to-use solution to their innovation needs, it was necessary to scout out different technological and industrial domains and to use solutions that were already known in novel ways, which was something Continuum could do very well.

Given the complexity and the high level of uncertainty characterizing the NPD problems in which brokers are usually involved, our analysis suggests that it is crucial, for the success of the collaboration, to establish appropriate mechanisms that ensure straightforward coordination and communication between the intermediary and its clients. For instance, Continuum pays particular attention to the development of several prototypes throughout the entire innovation process and uses them as a means to continuously interact with its clients. This is even more important if one considers how brokers work to deliver a solution to their clients. Brokers interpret the clients' needs and then choose the most appropriate sources of knowledge among the different options they have access to, which entails the need for an accurate alignment between the vision 
and needs of the client and of the broker. It is for this reason that brokers usually start the collaborative process with an "alignment and learning" activity that is aimed at refining the original project brief and sharing the expected project impacts (Colombo et al., 2011). The "alignment and learning" phase is of outmost importance for creating trust between the broker and the client, as noted by the Design Manager of Continuum: "The first phase of the collaboration is fundamental for establishing a good and trustworthy relationship with the client. How you are dressed, how you talk with the other team members, what you know about their products and experience ... all these aspects impact how you are accepted by the team of the client. [...] The most critical thing during the Alignment and Learning phase is to win the trust of and enter in close, personal relationship with those people that do not believe in the project. It is obviously much more difficult in shorter projects." The relevance of the "alignment and learning" activity is also confirmed by the interviews with the clients of Continuum, which suggest that a critical capability they had to develop to make the most out of the collaboration with the intermediary was to achieve a thorough alignment of the project's objectives with the intermediary (alignment) as well as to transfer to the intermediary the relevant knowledge about the industry in which they operate (learning). A poor alignment and learning phase can indeed undermine the successful completion of a project, as happened during Continuum's collaboration with a leading home appliances manufacturer. As noted by the Project Leader of the manufacturing firm: "We were unable to coordinate ourselves with Continuum and to communicate to them that our priority was not to develop a new product that was excellent from a technical point of view. Due to this apparently stupid mistake, we lost several months and a lot of money on this project" Therefore, it seems that the priority for a firm willing to collaborate with a broker is to develop strong coordination capabilities (Jansen et al., 2005). Our analysis suggests that this can be done, for instance, by organizing the team working with the broker in the form of a joint task force and using the design brief $^{2}$ as a knowledge sharing tool that is continuously analyzed, reviewed and updated from the time the collaboration began. This was a common practice in all 3 projects that were considered in our study (see Table 2). As noted, for instance, by the Project Leader of a

\footnotetext{
${ }^{2}$ According to Borja de Mozota (2003), the design brief activates the concept generation and it consists of three main elements: the design project objective, information about the client company and information about the project.
} 
shoe manufacturer with which Continuum worked a few years ago: "The fact of having a unique repository containing all the relevant information regarding the goals of the project, our requirements and expectations, as well as Continuum's decisions, that served as a shared platform around which the joint task force took critical decisions, was of paramount importance for ensuring continuous coordination with the provider and easing the progress of the project".

\subsection{Mediator}

Mediators (see Figure 5) select the most appropriate solvers based on the fit between their capabilities and the client's problem (Access Sources). They then give the clients access to their contacts and, in so doing, favor potential collaborations (Delivery Contacts). Companies such as Material ConneXion, YourEncore, Experts Exchange and PerInnovare adopt this intermediary strategy (see Appendix A).

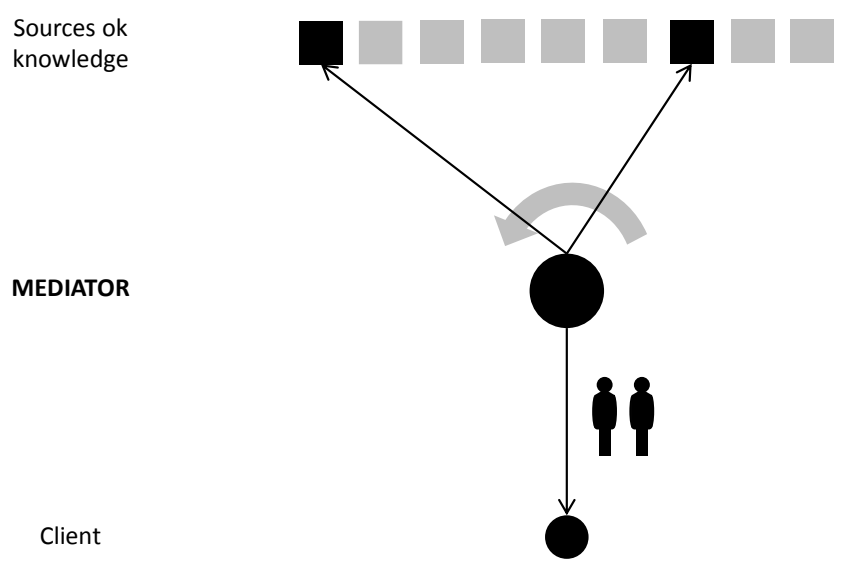

Figure 5: Innovation Intermediary - Mediator

Similarly to brokers, mediators are able to acquire deep knowledge distributed in different domains during the access stage of the intermediary process thanks to their knowledge about who has the right competencies required to solve their client's problems. Unlike brokers, however, mediators provide their clients with contacts and relationships with potentially valuable knowledge sources. While brokers exploit their network position by accessing and connecting separate knowledge domains, mediators introduce 
unconnected organizations to each other and ease communication and coordination in the delivery stage of the intermediary process (Dell'Era and Verganti, 2013). Leveraging these idiosyncratic abilities in both the access and delivery stages of the intermediation process, mediators usually help their clients address innovation problems that require deep scouting of specific knowledge domains and continuous monitoring of emerging innovation trends. For example, Material ConneXion describes itself on its website as: "made up of an international team of multidisciplinary experts that bridge the gap between science and design to create practical manufacturing solutions. [...] We act as a catalyst for new material and product ideas. We create new opportunities for product development and optimization". During the collaboration with BMW for the development of the GINA concept car (a visionary shape-shifting sports car made from polyurethane-coated lycra stretched over a wire aluminum frame), Material ConneXion did not develop the final material that was used for the concept car, but it provided two fundamental contributions. First, it inspired Chris Bangle (Chief of Design for BMW Group) by inviting him to an exhibition about tensions in architecture, where he noted the potential applications of high-strength and tear-resistant textiles. Second, it proposed an interesting selection of extremely tear-proof and resistant textiles with details about the firms that could manufacture them. As noted by Chris Bangle, Chief of Design for BMW Group: "[...] it dawned on me that we invest so much in sheet metal that we could be creating incredible emotion at virtually zero cost [...] I dedicated a team to work around this idea of fixed tooling, and for that, we went back to Material ConneXion, who we used as a very valuable resource to help us identify swatches that we could then develop into what would become the GINA." The key aspect that characterizes this class of innovation intermediaries is that mediators interpret and elaborate their clients' problems and select the most suitable sources of knowledge, therefore connecting their clients with the appropriate knowledge expert. In other words, mediators do not provide solutions to their clients, but contacts. Therefore, firms willing to collaborate with a mediator have to be able to clearly transfer to the intermediary their needs and their knowledge about the specific innovation problem, i.e., to perform an adequate "alignment and learning" activity to enable the mediator to identify the most appropriate knowledge domains to tap into. Furthermore, clients have to be open enough to 
understand and evaluate, without cognitive barriers, the potential contributions from organizations that are usually unknown, operate in very different industries and have dissimilar backgrounds and goals.

The interviews with the Material ConneXion clients indicate that this requires developing the ability to transfer tacit knowledge to the intermediary and to easily establish trusting relationships with the potential partner identified by the intermediary. The first issue often brings the intermediary to reiterate the first draft of the design brief in a document where its own interpretation of the problem is illustrated. For this reason, the brief becomes a critical tool through which the intermediary and its clients share reciprocal knowledge and align themselves before project activities start. Similar to the case of the broker, the establishment of a successful cooperation with a mediator requires that clients develop coordination capabilities (Jansen et al., 2005) that enable a rapid and effective alignment with the intermediary.

Regarding the need to establish a trustful relationship with the partner suggested by the mediator, a Manager in Material ConneXion says: "Especially in the collaborations with new clients, it happens that they like the proposed profile of the new partner, but then they decide to scout it in their network. After some collaborations, our clients trust not only the profile we propose but also the partner we suggest. They develop the capability to establish trust with organizations outside their network, which is key for the success of the collaboration". Our analysis suggests that clients should develop socialization capabilities to extract the maximum value from the collaboration with a mediator (Jansen et al., 2005). This is consistent with the existing literature that recognizes the importance of socialization capabilities in favoring the collaboration with external partners and enhancing the capability to assess, without cognitive boundaries, the contributions of distant and heterogeneous potential partners (Adler and Kwon, 2002). Our analysis suggests that firms can strengthen their socialization capabilities during their collaboration with a mediator by involving in the project team people with highly heterogeneous competence backgrounds, industrial experience and functional belonging. The Project Leaders we interviewed in the 3 firms that collaborated with Material ConneXion (i.e., BMW, PUMA and Aveda) noted that the eclectic nature of the team strongly reduces the cognitive barrier that often prevents firms from giving an objective evaluation of an opportunity coming from outside their boundaries, which is also known as Not-Invented-Here syndrome (Laden, 1996). 


\subsection{Collector}

Collectors (see Figure 6) ask the members of their innovation network to provide solutions regarding specific innovation problems faced by their clients (Access Proposals). Afterwards, they help their clients select the most appropriate solutions (Delivery Solutions). The collector strategy is used by intermediaries such as Aedoto, BootB, Innocentive and Ninesigma (see Appendix A).

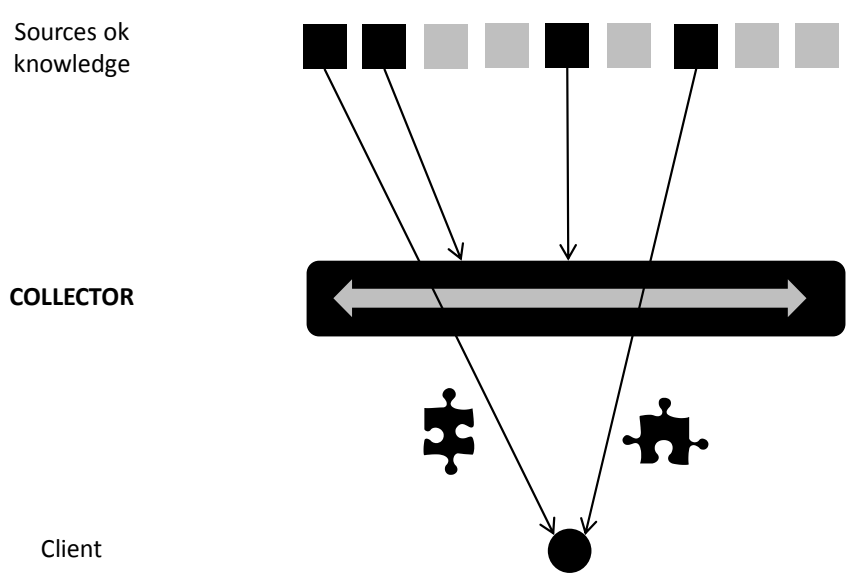

Figure 6: Innovation Intermediary - Collector

More specifically, collectors allow their clients to attract many different solutions from the members (usually individuals) of their large network. This is feasible thanks to the capabilities developed by collectors regarding how to access different knowledge domains. In particular, collectors make the innovation problems of their clients visible to their large networks of experts active in different fields. Collectors do not know in advance which are the relevant knowledge domains to tap to solve the clients' innovation problems, but they know perfectly how to solicit solutions from experts in their network. At the end of this process, collectors share with their clients the solution(s) they received, and the client chooses the best solution(s) and awards the proposer(s). Put differently, collectors deliver to their clients solutions based on competences belonging to different knowledge domains. The idiosyncratic characteristics of collectors explain why they are particularly 
suited to help their clients address "idea factoring" problems, in which there is a benefit from receiving a high number of novel alternatives coming from different knowledge domains. Our analysis suggests that collectors usually support their clients in the fuzzy front end of the NPD process by identifying novel ideas for new products and services (as in the case of Aedo-to and BootB) or by searching for technologies that enable novel functionalities (as happens with Innocentive and Ninesigma). As noted by the Founder of Aedo-to.com: "Aedo-to offers to its clients the possibility to collect fresh ideas for new product development projects in an easy and cost-effective way thanks to the involvement of a community of creative people. Aedo-to.com is indeed able to provide, on average, 400 concepts for each new product creation brief, assuring at least 30 (or 50 according to the duration and the total award of the completion) high-quality concepts." Similarly, BootB reports on its website: "Our Creators provide on average 214 solutions for every creative challenge you offer. Simply publish your creative brief, receive loads of creative solutions, purchase the best!" The most important contribution of this class of innovation intermediaries is that they allow their clients to think "outside the box", as underlined by the Senior Manager of Aedo-to: "In order to design good sun-glasses, it is important to involve in the process people that have already designed sun-glasses, but also people that have never designed sun-glasses. The latter can bring new, fresh concepts by looking at the issue in a novel and unconventional way".

However, to extract the maximum benefit from the collaboration with collectors, client firms need to develop specific capabilities. In particular, our empirical evidence suggests that, given the high number of solutions that collectors are able to attract by tapping into their network of solvers, the critical challenge for firms wishing to interact with a collector is to develop effective procedures for timely and cost-effective screening of the solutions to their innovation problems identified through the help of the intermediary. Even if the collector usually provides suggestions about what solutions are best suited to the client's needs, the ultimate decision is in the hands of the client. Such decision-making processes can be very costly and complex, and there is a risk that the best ideas can be inadvertently screened out. This process requires the selection of formalized go/non-go criteria and qualitative methods that can be used to quickly reduce the large number of alternative solutions to a pool from which the best solution can be easily identified. The Founder of Aedo- 
to said: "The best firms, when they come to select the most promising ideas, have developed two alternative screening procedures. The first one consists in naming an external jury, comprising knowledgeable and wellrespected experts in the relevant knowledge domain(s). This usually works very well for identifying the best solution from a design perspective, avoiding the client having to choose a solution that is not characterized by a high level of innovativeness, but it is aligned with the client's established way of thinking. The second alternative is to define, at the beginning of the collaborative process, the criteria along which the solutions will be evaluated, creating something like a scoring tool. Usually those firms that adopt this method implement some pre-screening criteria to quickly reduce the number of solutions and then go through a detailed evaluation of the most promising solutions. This process works well to identify alternatives that are aligned with the client's needs even if there is the risk of penalizing radically new solutions." The importance of these practices is also highlighted by the Aedo-to clients we interviewed. For instance, the Project Leader in a manufacturer of household accessories (see Table 3) noted that: "If you don't have a good mechanism in place that allows you to quickly screen out the less promising solutions and to objectively evaluate those that are potentially useful to you, the opportunity to receive a large number of solutions can become a problem rather than a help! We have some experience in this regard and have learnt over time to apply structured, although qualitative, criteria for idea screening, plus involving some external advisors when necessary". This empirical evidence points, therefore, to the importance, for the collectors' clients, of developing system capabilities that increase the effectiveness of their solution screening process (Cohen and Bacdayan, 1994). In particular, these capabilities concern the establishment of appropriate organizational routines that increase the efficiency and effectiveness of the decision-making process, through the reduction of the effort required.

\subsection{Connector}

Connectors (see Figure 7) receive information regarding the experience and competencies of the members of their network that are willing to collaborate with their clients (Access Proposals) and allow the latter to choose those firms or individuals who are the most appropriate for working and collaborating with given a 
specific innovation problem (Delivery Contacts). The connector strategy is adopted by intermediaries such as TakeACoder, Odesk, Elance and GetACoder (see Appendix A).

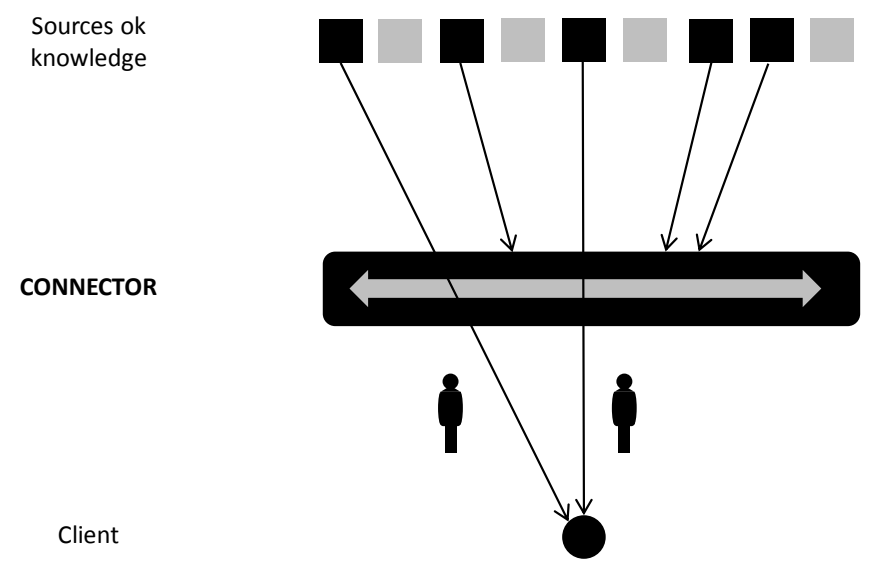

Figure 7: Innovation Intermediary - Connector

Connectors enable their clients to attract many different bids from experts active in different knowledge domains, leveraging the capabilities of the connector regarding how to access their network of experts. In particular, the connector asks the members of its community to provide a bid in which they describe their competencies, past experience, the delivery time and the compensation they require for working on the innovation problem. Similarly to collectors, connectors do not know which knowledge domains are necessary to look into to address the clients' innovation problems, but they know perfectly how to connect their clients with experts active in different technological and industrial domains. At the end of this process, connectors share all the bids received with the client that has the opportunity to select the most appropriate expert with which to collaborate. Based on this understanding of the peculiarities of the connector strategy, our analysis suggests that this category of intermediaries addresses experience-based innovation problems, characterized by clear requirements, that can be solved by relying on the contribution of low-cost experts. TakeACoder says on its website: "TakeACoder intends to redesign the business professional services market, giving to professionals a marketplace where they can sell their skills and knowledge to enterprises inside a framework maximize value for both. TakeACoder has been designed to be the first consulting firm of the 2.0 
era. Enterprise will find high skilled professionals to engage inside their projects or to who give the complete development of new ideas and services". Similarly, GetACoder says on its website: "Find Freelance Programmers, Web Designers and Freelance Writers for your next request. Outsource jobs to your home country or to countries where labor is cheap. Post a request for free and start receiving bids within minutes. Thousands of outsourced jobs prove that GetACoder is a cost-effective way to get the best talent in the world at an amazing low price. Grow your business and achieve a greater return on investment by using GetACoder". This point is clear in the words of the TakeACoder clients we interviewed. For instance, the Project Leader in a start-up that worked with the intermediary for the development of iPhone applications said: "We rely on intermediaries like TakeACoder when we need very specific expertise at much lower costs compared with traditional consultants."

Based on our analysis, it appears that the connector strategy has similarities with both the mediator and collector strategies. Like collectors, connectors leverage their capabilities to access their network of experts, requiring that their clients engage in a screening process aimed at identifying the most appropriate experts to collaborate with. This is confirmed, for instance, by a firm that worked with GetACoder and says on the website of the intermediary: "I worked on a coding problem for nearly a month. Two days after posting my job on GetACoder, I not only had a dozen programmers to choose from, but within minutes of picking a winner I had my problem solved. Next time, rather than banging my head against the wall, I'm going straight to GetACoder to get the job done!" The intermediary offers their clients the opportunity to receive many different bids for a specific innovation problem. The clients have to be able to identify the best solvers if they want to take advantage of the service. Therefore, systemic capabilities that allow the establishment and consistent application of effective screening routines are needed. The Project Leader of a start-up that worked with TakeACoder for the development of iPhone applications said: "Of course, to realize the benefits of this kind of collaboration, you need to define very clearly the type of problem that you have to address. This is the only way through which you can attract serious contributors". Furthermore, as with mediators, connectors deliver to their clients the know-who in terms of experts with whom to collaborate. To develop a solution to its innovation problems, the client has to be able to collaborate successfully with the selected 
experts. To this aim, firms relying on the service of a connector have to develop socialization capabilities that allow them to interact with individuals and companies with different backgrounds and experience to extract the maximum value from interacting with them. These socialization capabilities are even more critical here because with connectors, the interaction between clients and solvers usually takes place virtually, through the web. As noted by the Innovation Manager of a service firm that collaborated with TakeACoder: "After you select the right partner to work with, which is not an easy thing to do, you have to start working with him, which can be even more challenging unless you have strong interaction and communication abilities and you are open to receive contributions from external, unconventional sources." Connectors are usually very active in providing their clients with several tools that help them develop such systemic and socialization capabilities. For instance, connectors may allow their clients to provide feedback on the work performed by the solver, which enables a selection process based on their track record. Moreover, interactive and contentrich communication media (such as specifically designed live message boards) are used to streamline the communication and interaction between clients and solvers. As noted by the Project Leader of an ecommerce firm that worked with TakeACoder: "The online Private Message Board is something excellent that others do not have. This feature helps both parties to clarify things related to the project in real time". A synthesis of the findings of our empirical analysis is provided in Table 3. 


\begin{tabular}{|c|c|c|c|c|}
\hline & Broker & Mediator & Collector & Connector \\
\hline $\begin{array}{l}\text { Types of NPD } \\
\text { problems } \\
\text { addressed by the } \\
\text { intermediary }\end{array}$ & $\begin{array}{l}\text { Complex } \\
\text { innovation } \\
\text { problems } \\
\text { characterized by } \\
\text { unclear technical } \\
\text { and market } \\
\text { requirements that } \\
\text { entail } \\
\text { unpredictable } \\
\text { recombination of } \\
\text { existing knowledge. }\end{array}$ & $\begin{array}{l}\text { Innovation problems } \\
\text { requiring deep } \\
\text { scouting of specific } \\
\text { knowledge domains, } \\
\text { connections to } \\
\text { unknown sources of } \\
\text { competencies and } \\
\text { continuous } \\
\text { monitoring of } \\
\text { innovation trends. }\end{array}$ & $\begin{array}{l}\text { Idea factoring } \\
\text { problems, where } \\
\text { large number of } \\
\text { creative } \\
\text { alternatives should } \\
\text { be explored quickly } \\
\text { and effectively. }\end{array}$ & $\begin{array}{l}\text { Experience-based } \\
\text { innovation } \\
\text { problems, } \\
\text { characterized by } \\
\text { clear requirements, } \\
\text { that can be solved } \\
\text { by relying on the } \\
\text { contributions of } \\
\text { low-cost experts. }\end{array}$ \\
\hline $\begin{array}{l}\text { Examples of NPD } \\
\text { problems } \\
\text { addressed by the } \\
\text { intermediary }\end{array}$ & $\begin{array}{l}\text { Development of a } \\
\text { new product line } \\
\text { for a food company } \\
\text { that is entering a } \\
\text { new geographical } \\
\text { market. }\end{array}$ & $\begin{array}{l}\text { Identification of a } \\
\text { new packaging } \\
\text { solution able to } \\
\text { double the shelf-life } \\
\text { of a new food } \\
\text { product. }\end{array}$ & $\begin{array}{l}\text { Development of a } \\
\text { logo for a } \\
\text { manufacturing } \\
\text { company that } \\
\text { wants to strengthen } \\
\text { its image in the } \\
\text { market. }\end{array}$ & $\begin{array}{l}\text { Preparation of a 5- } \\
\text { year business plan } \\
\text { for an e-commerce } \\
\text { start-up company, } \\
\text { where farmers sell } \\
\text { their products } \\
\text { online directly to } \\
\text { consumers. }\end{array}$ \\
\hline $\begin{array}{l}\text { Capabilities } \\
\text { required to } \\
\text { collaborate with } \\
\text { the intermediary }\end{array}$ & $\begin{array}{l}\text { Coordination } \\
\text { capabilities that } \\
\text { allow rapid and } \\
\text { effective vision } \\
\text { alignment between } \\
\text { client and } \\
\text { intermediary. }\end{array}$ & $\begin{array}{l}\text { Coordination and } \\
\text { socialization } \\
\text { capabilities that allow } \\
\text { rapid and effective } \\
\text { vision alignment } \\
\text { between client and } \\
\text { intermediary and the } \\
\text { ability to collaborate } \\
\text { with suppliers from } \\
\text { different industries } \\
\text { and with different } \\
\text { experiences. }\end{array}$ & $\begin{array}{l}\text { System capabilities } \\
\text { that allow quick and } \\
\text { cost-effective } \\
\text { screening of many } \\
\text { ideas provided by } \\
\text { solvers belonging to } \\
\text { novel knowledge } \\
\text { domains. }\end{array}$ & $\begin{array}{l}\text { System and } \\
\text { socialization } \\
\text { capabilities that } \\
\text { allow quick and } \\
\text { cost-effective } \\
\text { screening of solvers } \\
\text { and ensure the } \\
\text { ability to } \\
\text { collaborate in a } \\
\text { virtual environment. }\end{array}$ \\
\hline $\begin{array}{l}\text { Examples of } \\
\text { practices that } \\
\text { enable capability } \\
\text { development }\end{array}$ & $\begin{array}{l}\text { Organize the } \\
\text { team working } \\
\text { with the broker } \\
\text { in the form of a } \\
\text { joint task force. } \\
\text { Use the design } \\
\text { brief as a } \\
\text { knowledge- } \\
\text { sharing tool } \\
\text { that is } \\
\text { continuously } \\
\text { analyzed, } \\
\text { reviewed and } \\
\text { updated from } \\
\text { the beginning } \\
\text { of the } \\
\text { collaboration. }\end{array}$ & 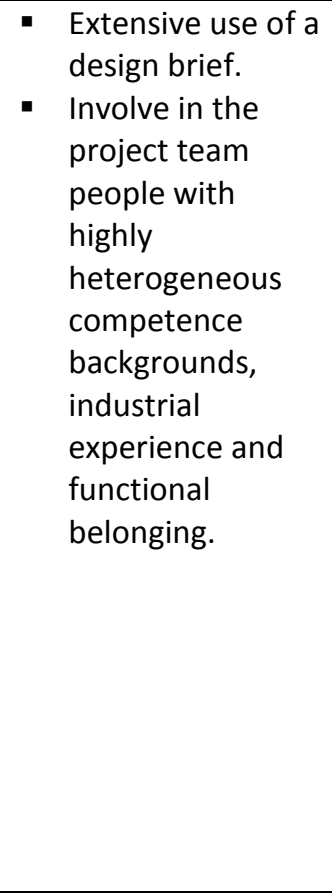 & $\begin{array}{l}\text { - Apply } \\
\text { formalized } \\
\text { go/non-go } \\
\text { criteria and } \\
\text { qualitative } \\
\text { methods that } \\
\text { help screen out } \\
\text { the solutions } \\
\text { proposed by } \\
\text { the } \\
\text { intermediary. } \\
\text { Involve in the } \\
\text { screening } \\
\text { process an } \\
\text { external jury } \\
\text { composed of } \\
\text { knowledgeable } \\
\text { experts in the } \\
\text { relevant } \\
\text { knowledge } \\
\text { domains. }\end{array}$ & $\begin{array}{l}\text { Use the tools } \\
\text { offered by the } \\
\text { connector (e.g., } \\
\text { systems that } \\
\text { track the } \\
\text { feedbacks } \\
\text { received over } \\
\text { time by the } \\
\text { solvers and live } \\
\text { message } \\
\text { boards) to } \\
\text { support the } \\
\text { selection } \\
\text { process and } \\
\text { streamline the } \\
\text { communication } \\
\text { between clients } \\
\text { and solvers. }\end{array}$ \\
\hline
\end{tabular}

Table 3: Summary of the case study findings 


\section{Conclusions}

NPD service providers and web-based innovation intermediaries provide a varied range of services that can help their clients improve the performance of the NPD process. Despite the increasing importance of this phenomenon, no efforts have been made thus far to propose a classification of the alternative strategies innovation intermediaries adopt to interact with their sources of knowledge and deliver value to clients.

This paper suggests that innovation intermediaries should be distinguished into four classes, labeled broker, mediator, collector and connector, based on how they access their sources of knowledge and deliver value to their clients. In particular, brokers are those intermediaries that identify the sources of knowledge that are best suited to address the needs of their clients, acquire pieces of knowledge from these sources and recombine them to provide a ready-to-use solution to their clients. Similar to brokers, mediators identify the most appropriate sources of knowledge based on the fit between them and their clients' problems. Afterward, they establish a relationship between these sources of knowledge and their clients, easing collaboration between them. Collectors are those intermediaries that ask that the members of their innovation network provide solutions regarding specific innovation problems faced by their clients. They then help their clients select the best solutions. Finally, connectors gather information regarding the experience and competences of the members of their network of knowledge sources (usually comprising both firms and individuals) and allow their clients to choose those members that are the most appropriate for working and collaborating with, considering the peculiarities of their innovation problem.

The multiple case study analysis presented in the paper suggests that the proposed typology is useful because each category of innovation intermediaries is, due to the approach it uses to access knowledge and deliver value to clients, more apt to address a specific class of NPD problems. Brokers are used to help their clients address complex innovation problems characterized by unclear technical and market requirements, which entail unpredictable recombinations of existing knowledge. Mediators, instead, help their clients with problems requiring deep scouting of specific knowledge domains and the monitoring of promising innovation 
trajectories. Innovative firms rely on collectors when they are confronted with idea factoring problems requiring a quick and effective exploration of a large number of creative alternatives, whereas connectors are used to help clients with experience-based NPD challenges that have clearly defined requirements. This represents a useful contribution to management practice, as it provides a first exploratory framework that helps firms confronted with an innovation problem identify the most appropriate intermediary on which to rely. These findings also have interesting policy implications. They suggest that to maximize the contribution of intermediaries to industrial innovation, policy intervention should take into proper account the consistency between the characteristics of different innovation intermediaries and the product innovation challenges they are involved in.

Our analysis also suggests that firms willing to interact with a particular category of innovation intermediary need to develop specific capabilities to extract the maximum value from the collaboration. Whereas coordination capabilities are necessary to interact successfully with brokers and mediators, collaboration with connectors and mediators requires special socialization skills. Finally, system capabilities are needed to successfully interact with collectors and connectors. This is a further practical implication of our study, which can help those innovative firms that have decided to invest time and money in the collaboration with a particular category of intermediary overcome the organizational barriers that might impede successful completion of the collaboration.

The paper also suggests theoretical implications, and its most important contribution is furthering research on open and collaborative innovation (Chesbrough, 2003; Pisano and Verganti, 2008). In particular, by suggesting that collaborating with a particular category of innovation intermediary requires consistency between the characteristics of the intermediary itself, the type of NPD problems to be addressed and the organizational capabilities of the client firm, it points to the contextual nature of open innovation practices, which is an area ripe for future research (West and Bogers, 2013).

Of course, this study has several limitations that point to the existence of other promising research opportunities. First, because of the exploratory nature of our multiple case study analysis, it is not possible to statistically generalize results to populations or firms or markets. Our aim was to make analytical and 
theoretical generalizations to the existing body of knowledge regarding intermediary strategies and the contribution of innovation intermediaries to the NPD process of their clients. The patterns linking the adherence to a particular intermediary strategy, the type of innovation problem addressed by the intermediary and the capabilities firms need when they collaborate with different categories of intermediaries unearthed by our study need to be subjected to further confirmatory empirical analyses using larger representative samples of innovation intermediaries and client firms. It is our intent that our preliminary findings will inform future theoretical and empirical studies regarding intermediary strategies and interactions between intermediaries and their clients. Second, this study focuses on the contribution of intermediaries to the NPD process of their clients, with the aim of identifying the types of innovation problems they address. Future research could examine the impact collaborating during product development with different classes of innovation intermediaries has on the performance of the NPD process in terms of speed, quality, market success and profitability. It would be interesting to understand under what conditions (e.g., type of NPD problem or characteristics of the client) each class of innovation intermediary (i.e., collector, connector, broker and mediator) has a more positive impact on NPD performance, thereby corroborating our preliminary findings concerning the type of NPD problem each class of intermediary seems more suited to address. In this vein, an intriguing avenue for future research is investigating the network characteristics of each class of innovation intermediary in terms of structural hole and structural autonomy and their relationships with the intermediaries' performance. Finally, integrated strategies, whereby an intermediary adopts more than a single approach to interact with its knowledge sources and clients (as IDEO has recently done with the OpenIDEO online platform), is a phenomenon that deservers further empirical investigation. 


\section{BROKER}

\section{IDEO}

[www.ideo.com]

\section{Frog Design}

[www.frogdesign.com]

Future Concept Lab

[www.futureconceptlab.com]

IDEO is an award-winning global design firm that takes a human-centered, design-based approach to helping organizations in the public and private sectors innovate and grow. They identify new ways to serve and support people by uncovering latent needs, behaviors, and desires. They envision new companies and brands and design the products, services, spaces, and interactive experiences that bring them to life. They help organizations build creative culture and the internal systems required to sustain innovation and launch new ventures.

frog works with the world's leading companies, helping them to design, engineer, and bring to market meaningful products and services. With an interdisciplinary team of more than 1,600 designers, strategists, and software engineers, frog delivers connected experiences that span multiple technologies, platforms, and media. frog works across a broad spectrum of industries, including consumer electronics, telecommunications, healthcare, energy, automotive, media, entertainment, education, finance, retail, and fashion. Clients include Disney, GE, HP, Intel, Microsoft, MTV, Qualcomm, Siemens, and many other Fortune 500 brands. Founded in 1969, frog is headquartered in San Francisco, with locations in Amsterdam, Austin, Boston, Chennai, Bangalore, Gurgaon, Johannesburg, Kiev, Milan, Munich, New York, Seattle, Shanghai, and Vinnitsa. frog is a company of the Aricent Group, a global innovation and technology services firm.

Future Concept Lab is a research Institute that stands out on the international landscape as one of the most advanced research centres specialized in marketing issues and trends in consumption. With extensive research activities in Europe, North America, South America and Asia, Future Concept lab was born as a global project. It is headquartered in Milan, and in January 2011 opened a new office in São Paulo (Brasil). Future Concept Lab has correspondents in twenty-five countries around the world, a reality present on a virtual platform: the Genius Loci Lab. The goal of Future Concept Lab is to develop and share new concepts regarding products, communication and distribution in order to enable clients to effectively deal with both the advanced and emerging markets, working in terms of the key words of the future. The Institute carries out integrated research projects based on specific methodologies that lead to the definition of sector-related scenarios, offers consultancy and training services, publishes works that represent the Institute's main activities, internationally and internally, like for instance the most recent book Consum-Authors.

\section{MEDIATOR}

\section{Presans}

[www.presans.com]

\section{Experts Exchange}

[www.experts-exchange.com]

[www.perinnovare.com]
Perlnnovare S.p.a

PRESANS is a French start-up that aims to connect business and expertise. In order to achieve this objective, the company has developed X-Search, a tool allowing automatic competence and expertise mapping (from scientific publications, patents, corporate websites, etc.). PRESANS clients simply describe their needs by a few keywords and X-Search will find the most relevant experts to address it among its database of over a million experts worldwide.

Experts Exchange is a technology help website. Its experts are real people with real-world technology experience from around the globe. Microsoft MVPs, IT consultants and many more. They volunteer their time to provide tech support in our patented Q\&A forums. If a firm has got a technology problem-big or small- Experts Exchange can help solve it. Experts Exchange works because it is a patented knowledge-sharing platform that enables people to work together to solve their technology problems. From routine system errors to complex coding bugs, Experts Exchange is where the world's top IT professionals come to find the solutions they need.

PerInnovare S.p.a is an Italian company that aims at supporting the innovation activities of its clients through the creation of ad hoc project teams. Perinnovare S.p.a has established over time a set of consolidated relationships with different subjects ranging from industrial firms to universities and research centers. By leveraging this network, the company is able to analyze and deeply understand the innovation problems of its clients and to create hoc project teams that include all the competences required to address the clients' innovation needs.

\section{COLLECTOR}

\section{BootB}

[www.bootb.com]

\section{Innocentive}

[www.innocentive.com]
BootB is the Pitching Engine that brings Brand Builders and Creative Brains together. What is the usual way Brands seek Creativity? If they have the opportunity to choose, they start a pitch and select the best proposal from a limited number of participants. BootB is designed as an online alternative to that process that has no offline limitations. The BootB platform is built to run Pitches. Firms can start your Pitch and obtain Solutions from an unlimited number of Creators from anywhere on the entire planet. InnoCentive is an open innovation and crowdsourcing pioneer that enables organizations to solve their key problems by connecting them to diverse sources of innovation, including employees, customers, partners, and the world's largest problem solving marketplace. Their proven Challenge Driven Innovation methodology, a community of millions of problem Solvers, and their cloud-based technology platform combine to fundamentally transform the economics of innovation and R\&D through rapid solution delivery and the development of sustainable open innovation programs. 


\begin{tabular}{|c|c|}
\hline & $\begin{array}{l}\text { Leading commercial, government, and nonprofit organizations such as Eli Lilly, Life Technologies, } \\
\text { NASA, nature.com, Popular Science, Procter \& Gamble, Roche, Rockefeller Foundation, and The } \\
\text { Economist partner with InnoCentive to solve problems and innovate faster and more cost effectively } \\
\text { than ever before. }\end{array}$ \\
\hline $\begin{array}{l}\text { Nine Sigma } \\
{[\text { www.ninesigma.com] }}\end{array}$ & $\begin{array}{l}\text { NineSigma is the most experienced and advanced Open Innovation service provider in the world. } \\
\text { Founded in 2000, NineSigma has been offering open innovation solutions long before it was an } \\
\text { accepted management practice. In fact, NineSigma is responsible for a large part of how open } \\
\text { innovation is practiced today, and continues to evolve its services and organization to ensure that } \\
\text { your organization will be prepared to move to the next level of open innovation capability, regardless } \\
\text { of where you are today. They Engage companies across all industry sectors with the global innovation } \\
\text { community, and Enable their organizations to leverage their open innovation network of external } \\
\text { resources to solve immediate challenges, fill product pipelines and integrate new knowledge and } \\
\text { capabilities into their organizations. }\end{array}$ \\
\hline \multicolumn{2}{|r|}{ CONNECTOR } \\
\hline $\begin{array}{l}\text { oDesk } \\
\text { [www.odesk.com] }\end{array}$ & $\begin{array}{l}\text { oDesk is the marketplace for online workteams, with the best business model for both employers and } \\
\text { contractors. Its unique approach guarantees to employers that an hour billed is an hour worked, while } \\
\text { guaranteeing to contractors that an hour worked is an hour paid. This win-win approach attracts more } \\
\text { work to oDesk than to any other online work marketplace. Each month, thousands of companies of } \\
\text { all sizes post jobs on oDesk, representing more than } \$ 65,000,000 \text {. At the same time, hundreds of } \\
\text { thousands of top-notch professionals, including web developers, software programmers, graphic } \\
\text { designers, writers, customer service representatives and virtual assistants, offer their services } \\
\text { through oDesk. With an average job size of } \$ 5,000 \text {, oDesk is the best place to find meaningful work } \\
\text { and top-flight talent. More than doubling in size each year since } 2004 \text {, oDesk is where companies are } \\
\text { building their entire organizations online and is the primary source of income for thousands of } \\
\text { contractors. oDesk is truly changing how the world works. }\end{array}$ \\
\hline $\begin{array}{l}\text { Elance } \\
\text { [www.elance.com] }\end{array}$ & $\begin{array}{l}\text { As the world's leading platform for online employment, Elance helps businesses hire and manage in } \\
\text { the cloud. For businesses looking to staff-up a team on an hourly or project basis, Elance offers instant } \\
\text { access to qualified professionals who work online and provides the tools to hire, view work as it } \\
\text { progresses and pay for results. }\end{array}$ \\
\hline $\begin{array}{l}\text { GetACoder } \\
\text { [www.2rentacoder.com] }\end{array}$ & $\begin{array}{l}\text { GetACoder enables its clients to find Freelance Programmers, Web Designers and Freelance Writers } \\
\text { for working at every kind of innovation task. Thanks to its innovative business model, GetACoder helps } \\
\text { clients outsource jobs where labor is cheap. Clients can post a request for free and start receiving bids } \\
\text { within minutes. Thousands of outsourced jobs prove that GetACoder is a cost-effective way to get the } \\
\text { best talent in the world at an amazing low price. }\end{array}$ \\
\hline
\end{tabular}

\section{Appendix B: interview protocol (interviewees working for the intermediary)}

Main questions regarding the intermediary and its strategy:

- What is the business model adopted by (name of the intermediary)?

- How does the intermediary access and explore different sources of knowledge?

- Does the intermediary implement specific tools to access and explore different sources of knowledge?

- How does the intermediary disclose different knowledge domains to its client?

- Does the intermediary develop any specific tool to disclose knowledge to its clients?

- What benefits does collaborating with you confer to your clients?

- What are the main problems clients face during the collaboration?

- What are the main issues clients want to solve in collaborating with you? 
- Can you please identify other intermediaries that are similar to you? Why they are similar? What are the main differences with them? Which kinds of innovation problems do they try to solve? Why should a client choose you rather than another intermediary?

The main questions regarding each innovation project considered in the study:

- Can you please give us a brief description of the project?

- What are the main benefits the client receives from the collaboration?

- What are the main problems you faced during the collaboration with the client?

- What could you improve in similar collaboration projects?

\section{Appendix C: interview protocol (interviewees working for the intermediary's clients)}

The main questions regarding each innovation project considered in the study:

- Why did you choose to collaborate with an NPD service provider to solve this particular kind of innovation problem?

- How do you define this type of innovation problem? Does it differ according the innovation problems you usually have to face?

- Do you think you could solve similar innovations problems more effectively with other intermediaries? Why?

- What factors could hinder future collaborations with the intermediary?

- Do you plan to engage in similar collaboration projects in the future? 


\section{References}

Abecassis-Moedas, C., Mahmoud-Jouini, S.B., Dell'Era, C., Manceau, D. and Verganti, R. (2012) Key resources and internationalization modes of creative knowledge-intensive business services: the case of design consultancies. Creativity and Innovation Management, 21, 3, 315-331.

Adler, P.S. and Kwon, S. (2002) Social capital: Prospects for a new concept. Academy of Management Review, 27, 1, 17-40.

Bianchi, M., Chiesa, V. and Frattini. F. (2011) Selling technological knowledge: how firms can win the complexities of technology transactions. Research-Technology Management, 54, 2, 18-26.

Boudreau, K., Lacetera, N. and Lakhani, K. (2011) Incentives and Problem Uncertainty in Innovation Contests: An Empirical Analysis. Management Science, 57, 5, 843-863.

Burt, R.S. (2004) Structural holes and good ideas. American Journal of Sociology, 110, 2, 349-399.

Chao, G.T., O'Leary-Kelly, A.M., Wolf, S., Klein, H.J. and Gardner, P.D. (1994) Organizational socialization: Its content and consequences. Journal of Applied Psychology, 79, 5, 730-743.

Chesbrough, H. (2003) Open Innovation: the new imperative for creating and profiting from technology. Harward Business School Press, Boston, MA.

Chesbrough, H. (2006) Open Business Models: How to Thrive in the New Innovation Landscape. Boston: Harvard Business School Press, Boston, MA.

Chiesa, V., De Massis, A., Frattini, F. and Manzini, R. (2007) How to sell technology services to innovators: evidence from nanotech Italian companies. European Journal of Innovation Management, 10, 4, 510-531.

Chiaroni, D., Chiesa, V., De Massis, A. and Frattini, F. (2008) The knowledge bridging role of technical and scientific services in knowledge-intensive industries. International Journal of Technology Management, 41, 3/4, 249-272.

Cohen, M.D. and Bacdayan, P. (1994) Organizational routines are stored as procedural memory. Organization Science, 5, 4, 554-568.

Cohen, W. and Levinthal, D. (1990) Absorptive capacity: A new perspective on learning and innovation. Administrative Science Quarterly, 35, 1 128-152.

Colombo, G., Dell'Era, C. and Frattini, F. (2011) New Product Development (NPD) service suppliers in Open Innovation practices: Processes and organization for knowledge exchange and integration. International Journal of Innovation Management, 15, 1, 165-204.

Colombo, G., Klanner, I.M., Roiser, S. and Buganza, T. (2013) Web-based intermediaries and problem typologies: an explorative study. International Journal of Innovation Management, 17, 2, 1-24.

Czarnitzki D and Spielkamp A (2000) Business services in Germany: bridges for innovation. ZEW discussion paper, 00-52. Mannheim.

Dell'Era, C. and Verganti, R. (2013) Relational strategies to connect technology and design: technology brokering and mediating. International Journal of Technology and Intelligence Planning, Vol. 9, No. 1, Pp. 1025.

Eisenhardt, K.M. and Graebner, M.E. (2007) Theory building from cases: opportunities and challenges. Academy of Management Journal, 50, 1, 25-32.

Eisenhardt, K.M. (1989) Building theories from case study research. Academy of Management Review, 14, 4, 532-550.

Eisenhardt, K.M. and Martin, J.A. (2000) Dynamic capabilities: What are they?. Strategic Management Journal, 21, 10/11, 1105-1121. 
Fisher, C.D. (1986) Organizational socialization: An integrative review. Research in Personnel and Human Resource Management, 4, 101-145.

Gassmann, O., Daiber, M., and Enkel, E. (2011) The role of intermediaries in cross-industry innovation processes. R\&D Management, 41, 5, 457-469.

Hargadon, A. and Sutton, R. (1997) Technology brokering and innovation in a product development firm. Administrative Science Quarterly, 42, 4, 716-749.

Hargadon, A. and Sutton, R. (2000) Building an innovation factory. Harvard Business Review, 78, 3, 157-166. Hargadon, A.B. (1998) Firms as knowledge brokers: Lessons in pursuing continuous innovation. California Management Review, 40, 3, 209-227.

Henderson, R. and Cockburn, I. (1994) Measuring competence? Exploring firm effects in pharmaceutical research. Strategic Management Journal, 15, Issue Supplement S1, 63-84.

Howells, J. (2006) Intermediation and the role of intermediaries in innovation. Research Policy, 35, 5, 715728.

Huston, L. and Sakkab, N. (2006) Connect and develop inside Procter \& Gamble's new model for innovation. Harvard Business Review, 84, 3, 58-66.

Jansen, J. J. P., Van den Bosch, F. A. J. and Volberda, H.W. (2005) Managing potential and realized absorptive capacity: how do organizational antecedents matter?. Academy of Management Journal, 48, 6, 999-1015.

Jeppesen, L.B. and Lakhani, K. (2010) Marginality and Problem Solving Effectiveness in Broadcast Research. Organization Science, 21, 5, 1016-1033.

Kodama, F. (1992) Technology fusion and the new R\&D. Harvard Business Review, July-August, 70-78.

Kogut, B. and Zander, U. (1992) Knowledge of the firm, combinative capabilities, and the replication of technology. Organization Science, 3, 3, 383-397.

Laden, K. (1996) 'Not invented there,' or, the other person's dessert always looks better!. Research Technology Management, 39, 6, 10.

Lynn, L., Reddy, M. and Aram, J. (1996) Linking technology and institutions: the innovation community framework. Research Policy, 25, 1, 91-106.

Lundvall, B-A. and Johnson, B. (1994) The learning economy. Journal of Industry Studies, 1, 2, 23-42.

McEvily, B. and Zaheer, A. (1999) Bridging ties: a source of firm heterogeneity in competitive capabilities. Strategic Management Journal, 20, 12, 1133-1156.

Miles, I. (2000) Services innovation: coming of age in the knowledge-based economy. International Journal of Innovation Management, 4, 4, 371-389.

Miles, M. B. and Huberman, A. M. (1994) Qualitative Data Analysis: an expanded sourcebook, Sage, Thousand Oaks, CA.

NSF (2010) Science and Engineering Indicators 2010.

Millson, M.R. and Wilemon, D. (2002) The impact of organizational integration and product development proficiency on market success. Industrial Marketing Management, 31, 1, 1-23.

O'Farrell, P.N. and Wood, P.A. (1999) Formation of strategic alliances in business services: towards a new client-oriented conceptual framework. The Services Industries Journal, 19, 1, 133-151.

Obstfeld, D. (2005) Social Networks, the Tertius lungens Orientation, and Involvement in Innovation. Aministrative Science Quarterly, 50, 100-130.

Pisano, G.P. and Verganti, R. (2008) Which kind of collaboration is right for you?. Harvard Business Review, $86,12,76-86$. 
Polanyi, M. (1966) The logic of tacit inference. Philosophy, 41, 155, 1-18.

Schumpeter, J. (1934) The theory of Economic Development. Cambridge, MA. Harvard University press.

Seaton, R.A.F. and Cordey-Hayes, M. (1993) The development and application of interactive model of industrial technology transfer. Technovation, 13, 1, 45-53.

Singh, J. and Fleming, L. (2010) Lone inventors as sources of breakthroughs: myth or reality?. Management Science, 56, 1, 41-56.

Souder, W.E., Sherman, J.D. and Davies-Cooper, R. (1998) Environmental Uncertainty, Organizational Integration, and New Product Development Effectiveness: A Test of Contingency Theory. Journal of Product Innovation Management, 15, 6, 520-533.

Stankiewicz, R. (1995) The role of the science and technology infrastructure in the development and diffusion of industrial automation in Sweden. In: Carlsson, B. (Ed.), Technological Systems and Economic Performance: The Case of Factory Automation, Dordrecht. Kluwer, 165-210.

Terwiesch, C. and Xu, Y. (2008) Innovation contests, open innovation, and multiagent problem solving. Management Science, 54, 9, 1529-1543.

Tran, Y., Hsuan, J. and Mahnke, V. (2011) How do innovation intermediaries add value? Insight from new product development in fashion markets. R\&D Management, 41, 1, 80-91.

Van den Bosch, F.A. J., Volberda, H.W., and de Boer, M. (1999) Coevolution of Firm Absorptive Capacity and Knowledge Environment: Organizational Forms and Combinative Capabilities. Organization Science, 10, 5, 551-568.

Verona, G., Prandelli, E. and Sawhney, M. (2006) Innovation and Virtual Environments: Towards Virtual Knowledge Brokers. Organization Studies, 27, 6, 765-788.

West, J. and Bogers, M. (2013). Leveraging external sources of innovation: a review of research on open innovation, Journal of Product Innovation Management, forthcoming.

Yin, R.K. (1984) Case Study Research, Design and Methods. London: Sage Publications. 